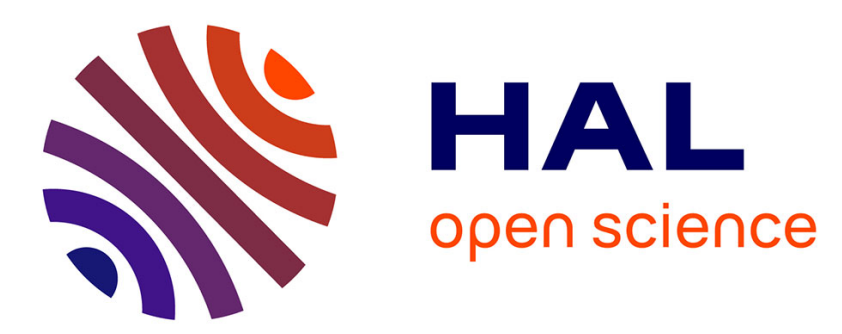

\title{
On the Measurement of Cooperative Compatibility to Predict Meaning Variance \\ Pierre-Emmanuel Arduin
}

\section{To cite this version:}

Pierre-Emmanuel Arduin. On the Measurement of Cooperative Compatibility to Predict Meaning Variance. IEEE International Conference on Computer Supported Cooperative Work in Design (CSCWD) 2015, May 2015, Calabria, Italy. pp.42-47, 10.1109/CSCWD.2015.7230931 . hal01194819

\section{HAL Id: hal-01194819 https://hal.science/hal-01194819}

Submitted on 7 Sep 2015

HAL is a multi-disciplinary open access archive for the deposit and dissemination of scientific research documents, whether they are published or not. The documents may come from teaching and research institutions in France or abroad, or from public or private research centers.
L'archive ouverte pluridisciplinaire HAL, est destinée au dépôt et à la diffusion de documents scientifiques de niveau recherche, publiés ou non, émanant des établissements d'enseignement et de recherche français ou étrangers, des laboratoires publics ou privés. 


\title{
On the Measurement of Cooperative Compatibility to Predict Meaning Variance
}

\author{
Pierre-Emmanuel Arduin \\ PSL, Université Paris-Dauphine, DRM UMR CNRS 7088 \\ Place du Maréchal de Lattre de Tassigny, 75016 Paris, France \\ Email: pierre-emmanuel.arduin@dauphine.fr
}

\begin{abstract}
Computer Supported Cooperative Work may rely on information technology in order to share information regardless where stakeholders are. Nevertheless, cooperative work needs more than just information sharing, notably because of meaning variance.

Considering that during cooperative work the same information may have different meanings from one person to another, we propose an approach in order to predict meaning variance by measuring cooperative compatibility. We study the expectations individuals may have from their colleagues during a given cooperative work. Such study leads to the measurement of cooperative compatibility, which has been used to predict meaning variance.
\end{abstract}

The calculation method proposed, as well as its relationships with meaning variance are discussed in this paper and currently tested within organizations.

\section{INTRODUCTION}

Information technology gives individuals the means to work together even if they are not in the same physical place. Information technology ensures information sharing between individuals, nevertheless authors as [19] highlight how much cooperative work needs more than just information sharing, leading to focus on innovation and knowledge intensive approaches for Computer Supported Cooperative Work. Indeed, knowledge is a resource necessary to realize processes ([5]), and it results of the interpretation by someone of information ([20]). Such information may be processed, stored and disseminated through information systems, but it is not knowledge, due to the possibility of meaning variance.

Within organizations, and particularly within extended enterprises, i.e. a network of firms collaborating in a project to achieve a common goal ([18]), the limit of computers is reached when there is no awareness that during cooperative work the same information shared through the same information system may lead to create different knowledge from one person to another ([11], [21], [2]), i.e. may lead to meaning variance.

In this paper, we propose an approach to measure how much individuals have common expectations from each other during a given cooperative work in order to highlight those who might create different knowledge from the same information. In other words, our approach aims at measuring cooperative compatibility in order to predict meaning variance.

After introducing background theories in the area of knowledge management, and particularly on the way different knowledge may be created from the same information, our approach is explained and discussed, from the interviewing of the respondents to the prediction of meaning variance through the measurement of cooperative compatibility.

\section{BACKGROUND THEORY AND ASSUMPTIONS}

The work presented in this paper relies on the assumption that two individuals may give different meanings to the same information. The way we give a meaning to information relying on knowledge management theories is introduced in this section.

As the author of this paper, I have got tacit knowledge, i.e. an individual cognitive construction, that I have structured into information during a process of sense-giving by writing these words. As the reader of this paper, you have interpreted this information by perceiving forms and colors, during a process of sense-reading. You have created new tacit knowledge that has a meaning for you (see Fig. 1). Such meaning may differ from one person to another

For R.L. Daft and K.E. Weick, "Interpretation gives meaning to data, but it occurs before organizational learning and action." ([3], p. 286), that it the reason why we consider that predicting meaning variance could be useful during Computer Supported Cooperative Work. Authors as T.K. Haavik in [6] have already focused on meaning during Computer Supported Cooperative Work in the case of safety-critical operations. Indeed during cooperative work, information may be shared, stored and disseminated through an information system. Nevertheless, as knowledge is the result of the interpretation by someone of information ([20]), information may have different meanings from one person to another. Meaning is given to information during processes introduced and studied by M. Polanyi in [17]. He notably focuses on the way we read a sense in information that we perceive (by listening or by reading for example). He considers sense-giving and sensereading processes, and he defines them as follows: "Both the way we endow our own utterance with meaning and our attribution of meaning to the utterances of others are acts of tacit knowing. They represent sense-giving and sensereading within the structure of tacit knowing." ([17], p. 301). For S. Tsuchiya: "When information is sense-read through interpretative framework, it becomes knowledge." ([20], p. 88). Such concept of interpretative framework has already been studied in the literature, being related to the concept of mental model ([1], [8], [15]).

Information is continuously interpreted through sensereading processes. During cooperative work, information may 


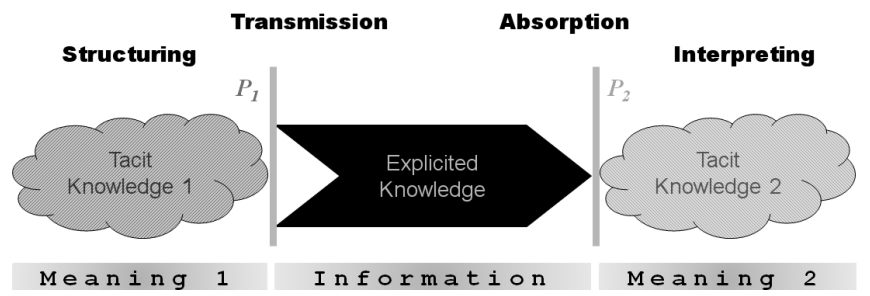

Fig. 1. Sharing information is not sharing knowledge, due to the possibility of meaning variance (Meaning 2 may differ from Meaning 1)

be transmitted by speaking, writing, acting, and also through information systems. Knowledge can then be:

- $\quad$ explicited, i.e. it has been made explicit by someone within a certain context, it is socially constructed and can be supported by information technology such as information. Individuals, as well as computers are "information processing systems" ([7], p. 9),

- tacit, it is not always articulated and cannot always be articulated, relying on [16] notably: "we can know more than we can tell".

So that explicited knowledge is tacit knowledge that has been made explicit by someone within a certain context. It is information source of tacit knowledge for someone else. It is "what we know and can tell" answering to [16] quoted above. The term explicit knowledge is often used ([13] and [14], notably), whereas it does not reflect the dynamic of the sense-giving process as well as the term explicited knowledge. Indeed such process is attached to a certain person acting within a certain context. That is the reason why we prefer to use the term explicited knowledge, which clearly shows how every piece of information can be seen as a piece of tacit knowledge that has been made explicit by someone within a certain context.

One interprets information and creates a piece of tacit knowledge, which has a meaning for him/her. During cooperative work, there may be someone who has received the same information and, interpreting it, has created a piece of tacit knowledge, which has a meaning for him/her. Such meaning may differ from one person to another, this is meaning variance.

\section{OUR ApPROACH to Predict MEANing VARIANCE BY MEASURING COOPERATIVE COMPATIBILITY}

The idea of measuring cooperative compatibility to predict meaning variance relies on [12], where Y. Murakami considers that there exists a "common denominator" of meanings given by several individuals to the same information. We argue that such common denominator may be predicted by measuring cooperative compatibility for a sample of individuals.

The formalism used by our approach is introduced in the first part of this section. The approach and its protocol are then presented in the second part of this section. A discussion on the construct validity of cooperative compatibility is finally proposed in the last part of this section.
A. Introducing a Formalism on Cooperative Compatibility and Meaning Variance

Throughout experimentations within industrial fields, we observed that the predisposition of individuals to give the same meaning to the same information may be related to the expectations they have from each other during a given cooperative work. The idea of our approach is to associate to each person $i \in \mathbb{N}$ a surface $S_{i}$, corresponding to his/her expectations $\Sigma_{i}$ from his/her colleagues during a given cooperative work. For all pairwise distinct persons $i, j \in \mathbb{N}$, we denote by $\Sigma_{i} \cap \Sigma_{j}$ the value of their cooperative compatibility. The surfaces $S_{i}$ and $S_{j}$ will have a large area of intersection if and only if $\Sigma_{i} \cap \Sigma_{j}$ is high, and this area will be small if and only if $\Sigma_{i} \cap \Sigma_{j}$ is low.

Then for three distinct persons $i, j, k \in \mathbb{N}$, the cooperative compatibility of the persons $i$ and $j$ is higher than the cooperative compatibility of the persons $i$ and $k$ (i.e. $\Sigma_{i} \cap \Sigma_{j}>\Sigma_{i} \cap \Sigma_{k}$ ) if and only if the surfaces $S_{i}$ and $S_{j}$ have a larger area of intersection than the one of $S_{i}$ and $S_{k}$ (i.e. $S_{i} \cap S_{j}>S_{i} \cap S_{k}$ ), meaning that:

$$
\begin{gathered}
\forall i, j, k \in \mathbb{N}, i \neq j \neq k, \\
S_{i} \cap S_{j}>S_{i} \cap S_{k} \Leftrightarrow \Sigma_{i} \cap \Sigma_{j}>\Sigma_{i} \cap \Sigma_{k}
\end{gathered}
$$

The order between such areas $\left(S_{i} \cap S_{j}\right)$ induces an ordering of cooperative compatibilities $\left(\Sigma_{i} \cap \Sigma_{j}\right)$.

We postulate that meaning variance is strongly related to cooperative compatibility: the higher cooperative compatibility is, the lower is meaning variance. This is a strong postulate of our approach, which is currently confronted with industrial fields. For all pairwise distinct persons $i, j \in \mathbb{N}$, let $\Delta \mu_{i, j}$ be the meaning variance between these two persons during a given cooperative work. Our proposition relies on the postulate that for three distinct persons $i, j, k \in \mathbb{N}$, the meaning variance between persons $i$ and $j$ is lower than the meaning variance between persons $i$ and $k$ (i.e. $\Delta \mu_{i, j}<\Delta \mu_{i, k}$ ) if and only if the cooperative compatibility of the persons $i$ and $j$ is higher than the cooperative compatibility of the persons $i$ and $k$ (i.e. $\Sigma_{i} \cap \Sigma_{j}>\Sigma_{i} \cap \Sigma_{k}$ ), meaning that:

$\forall i, j, k \in \mathbb{N}, i \neq j \neq k, \Sigma_{i} \cap \Sigma_{j}>\Sigma_{i} \cap \Sigma_{k} \Leftrightarrow \Delta \mu_{i, j}<\Delta \mu_{i, k}$

Meaning variance may now be predicted through the measurement of cooperative compatibility. Nevertheless such measurement needs the elaboration of surfaces representing individuals' expectations from each other during a given cooperative work. Let us now present the way of collecting such data.

\section{B. Predicting Meaning Variance by Measuring Cooperative Compatibility}

We are now aiming at collecting data on the expectations individuals may have from their colleagues during a given cooperative work. We absolutely banned the use of a formal framework produced a priori and we proposed to give respondents the means to produce their own framework by designing axes they consider relevant in order to characterize their expectations from each other during a given cooperative work. 


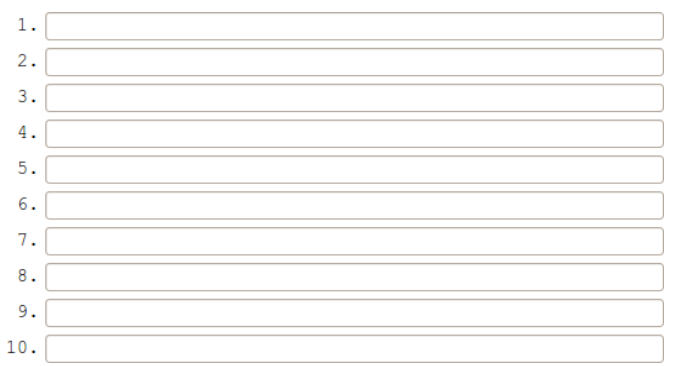

Fig. 2. Extract of the first form, maximum ten answers are expected from each respondent

The considered sample of respondents is composed of 10 persons (5 $5 \sigma^{7}$ and 5 \% ) with an average age of 30 years. Respondents have the following professional profiles: 3 are computer scientists, 2 are civil engineers, 2 work in the area of marketing, 2 are retired teachers, and 1 works in an hospital. These respondents do not work in the same organization and it is important to notice that the sample of respondents does not evolve between the first form and the second form. Collected data will concern this sample of respondents and will be irrelevant for another sample of respondents. So that in our approach the number of respondents is not as important as the diversity of their profiles. Indeed our approach relies on such diversity to highlight meaning variance by measuring cooperative compatibility.

After having introduced our study, we used a form in HTML in order to collect answers. Every respondent saw the following text:

\begin{abstract}
"You are going into a team asked to develop a Web site for a new client. You are an expert in this area and often confronted to colleagues less qualified than you are. From your point of view, what are the qualifications, skills, qualities and / or knowledge that should have your colleagues in order to successfully perform this project with you?

Take your time to answer, no more than ten dimensions.

When you are ready, click Send."
\end{abstract}

Then the respondent could see a form with ten open text fields (see Fig. 2) or contact us (we have never been contacted).

First of all we have to notice the ambiguity with which the question is asked: "qualifications, skills, qualities and / or knowledge". The question is quite open and leaded to a set of various and disordered answers, from "kindness" to "Web development (languages, libraries or frameworks)". These answers qualify what the considered sample of respondents could expect from colleagues during the given cooperative work. The answers have been gathered together into equivalence classes in order to design assessment axes. These axes allow to characterize respondents' expectations from their colleagues during the given cooperative work. In the case of our study, we obtained the following axes:

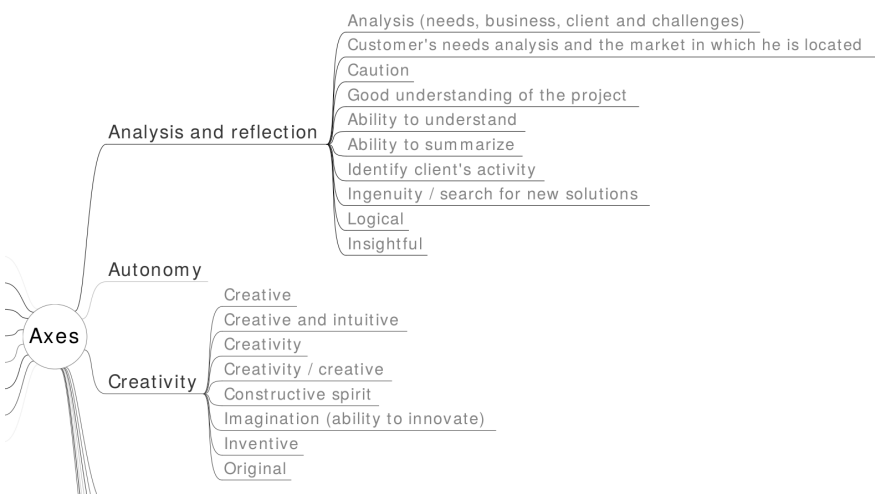

Fig. 3. Extract of the mind map representing the axes and the answers they gather

$\begin{array}{llll}\text { 1) } & \text { Writing } & \text { 10) } & \text { Rigor } \\ \text { 2) } & \text { Pedagogy } & 11) & \text { Timeliness } \\ \text { 3) } & \text { Openness } & 12) & \text { Patience } \\ \text { 4) } & \text { Computing } & 13) & \text { Marketing } \\ \text { 5) } & \text { Initiative } & 14) & \text { Graphics } \\ \text { 6) } & \text { Web Environment } & 15) & \text { Teamwork } \\ \text { 7) } & \text { Creativity } & 16) & \text { Curiosity } \\ 8) & \text { Autonomy } & 17) & \text { Communication } \\ \text { 9) } & \text { Analysis and reflection } & \text { 18) } & \text { Self-assessment }\end{array}$

The last axis (Self-assessment) has been added in order to weight the answers of each respondent. All the other axes result of a semantic gathering procedure that should be done as closely as possible from the respondents, for example through ethnographic fieldwork as proposed in [9] or [4]. We already proposed a procedure closer from the respondents through the use of cognitive maps ([1]), but which did not focus on cooperative compatibility. Indeed, we prefer gathering procedures involving the sense-reading and sense-giving processes of the person who is realizing them than gathering procedures involving information gathering software. The person who is gathering information can be aware of his/her sense-reading and sense-giving processes, contrary to information gathering software that relies on the sense-reading and sense-giving processes of the person who developed it.

The respondents are then invited to answer to a second form where they have to assess themselves on each axis in order to characterize their expectations from their colleagues during the given cooperative work. The axes are presented to the respondents in a mind map (see Fig. 3), so that they can find their answers to the first form and understand the meaning of each axis. The following text introduced the second form:

"This is the second part of the experiment. In the first part, you said what you considered important during a given cooperative work. Aggregated, your answers have induced axes covering the expectations of each one. The following mind map represents the different answers gathered into axes.

Read carefully the different answers gathered by each axis. Browse the map by trying to find your answers and by understanding the meaning of each axis. Then assess yourself on each axis on a scale from 0 (this axis does not represent me) to 10 (this axis represents me)." 
TABLE I. MEASURING COOPERATIVE COMPATIBILITY

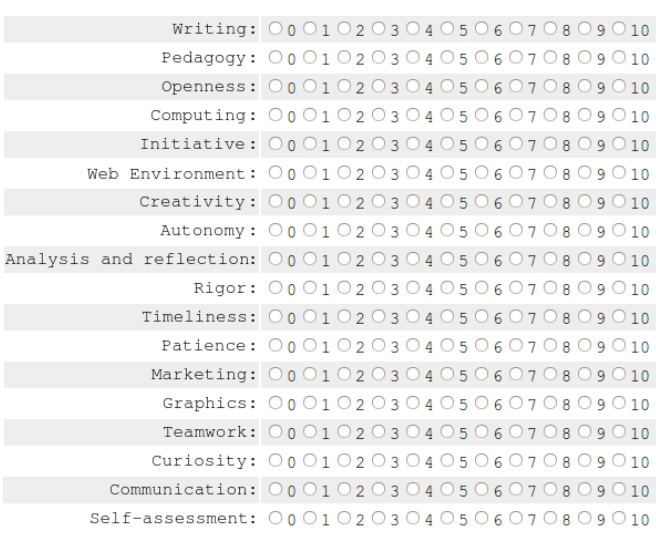

Fig. 4. Extract of the second form, each respondent have to assess himself/herself on each axis

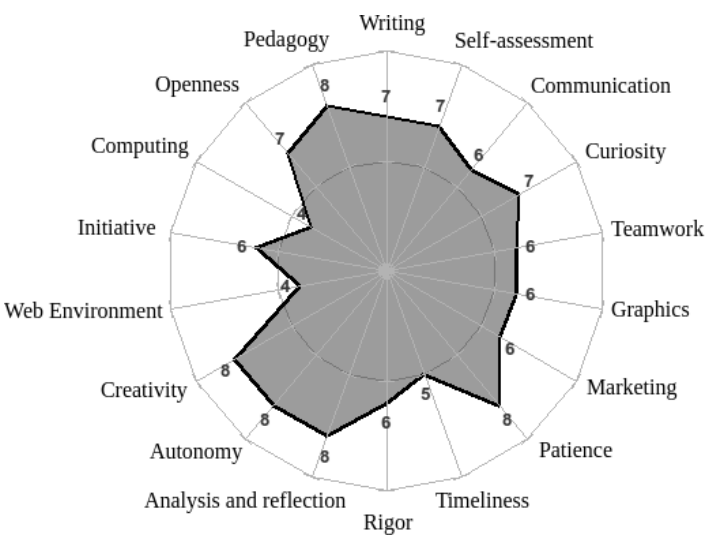

Fig. 5. A surface corresponding to the expectations of a respondent from his/her colleagues during the given cooperative work

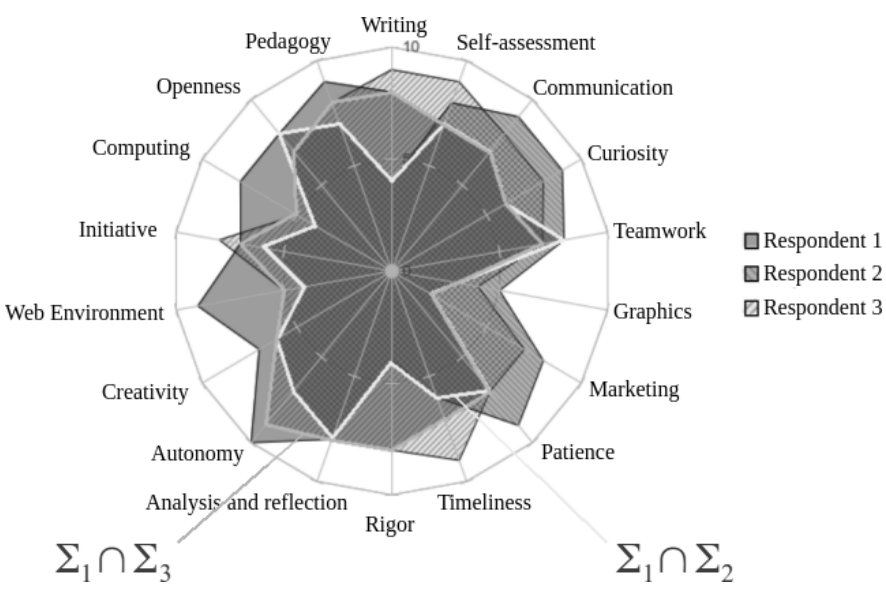

Fig. 6. Three respondents' expectations from their colleagues during the given cooperative work and their cooperative compatibilities

\begin{tabular}{l||c|c||c} 
& Resp. 1 & Resp. 2 & $\min \left(x_{i}, y_{i}\right)$ \\
\hline \hline Writing & 8 & 4 & 4 \\
\hline Pedagogy & 9 & 7 & 7 \\
\hline Openness & 8 & 8 & 8 \\
\hline Computing & 8 & 4 & 4 \\
\hline Initiative & 7 & 6 & 6 \\
\hline Web Environment & 9 & 4 & 4 \\
\hline Creativity & 7 & 6 & 6 \\
\hline Autonomy & 10 & 7 & 7 \\
\hline Analysis and reflection & 8 & 8 & 8 \\
\hline Rigor & 8 & 4 & 4 \\
\hline Timesliness & 7 & 6 & 6 \\
\hline Patience & 7 & 9 & 7 \\
\hline Marketing & 2 & 8 & 2 \\
\hline Graphics & 3 & 5 & 3 \\
\hline Teamwork & 8 & 8 & 8 \\
\hline Curiosity & 6 & 9 & 6 \\
\hline Communication & 7 & 9 & 7 \\
\hline Self-assessment & 7 & 8 & 7 \\
\hline \multicolumn{1}{c|}{$\Sigma_{x} \cap \Sigma_{y}=\sum_{i=1}^{n}$} & $\min \left(x_{i}, y_{i}\right)$ & & \\
& &
\end{tabular}

An extract of the second form is presented in Fig. 4. With the answers to this form it is possible to produce for each respondent a characterization of the expectations he/she has from his/her colleagues during the given cooperative work. Such characterization may be represented by a surface relying on the scores given by a respondent on each axis (see Fig. 5).

With such representation, it is possible to highlight how much two individuals have common expectations from each other during the given cooperative work. Cooperative compatibility being then higher for individuals with more common expectations. Fig. 6 represents three respondents' expectations and highlights their cooperative compatibilities. One can see in this figure that the cooperative compatibility of respondents 1 and 3 seems to be higher than the cooperative compatibility of respondents 1 and 2, i.e. $\Sigma_{1} \cap \Sigma_{3}>\Sigma_{1} \cap \Sigma_{2}$. In other words, meaning variance will be lower between respondents 1 and 3 than between respondents 1 and 2, i.e. $\Delta \mu_{1,3}<\Delta \mu_{1,2}$.

Nevertheless, this study lacks a measure more than representations. Let us now introduce a way of calculating for two surfaces representing two distinct respondents' expectations from their colleagues during the given cooperative work, the area of their intersection. We consider on each axis the minimal value of respondents' scores on this axis. For a form with $n$ axes, for all pairwise distinct respondents $x$ and $y$, on each axis $i \in \llbracket 1, n \rrbracket, x_{i}$ being the score of the first respondent and $y_{i}$ being the score of the second respondent, we propose a measure of cooperative compatibility defined by:

$$
\Sigma_{x} \cap \Sigma_{y}=\sum_{i=1}^{n} \min \left(x_{i}, y_{i}\right) .
$$

For the case of the respondents considered in Fig. 6, table I shows how cooperative compatibility is calculated for respondents 1 and 2 . The calculation leads to a cooperative compatibility of 104 for respondents 1 and 2 and of 117 for respondents 1 and 3 . So that respondents 1 and 3 have more common expectations from their colleagues during the given cooperative work than respondents 1 and 2 . We say that respondents 1 and 3 are more cooperatively compatible than respondents 1 and 2, and we predict that there will be less meaning variance between respondents 1 and 3 than between respondents 1 and 2 . 


\section{Discussing the Construct Validity of Cooperative Compatibility}

In this paper, we propose an approach to predict meaning variance by measuring cooperative compatibility. In psychometry, the construct validity of a measure reflects "the degree to which a measurement technique assesses the construct it is meant to assess" ([10], p. 600). There is high validity when: (1) "the measure performs in accordance with theoretically derived expectations", and (2) "the measure shows the expected relationships with other measures" ([10], p. 600). Let us now discuss the construct validity of the measure we proposed of cooperative compatibility.

1) The measure performs in accordance with theoretically derived expectations: Theoretically derived expectations aim here at doing cooperative compatibility increase when individuals have more common expectations from their colleagues during a given cooperative work. Inversely, cooperative compatibility will theoretically decrease when individuals have less common expectations from their colleagues during a given cooperative work. The calculation method we proposed defines cooperative compatibility as the sum of the minimum scores obtained by individuals on each axis defined by the first part of the experiment: $\Sigma_{x} \cap \Sigma_{y}=\sum_{i=1}^{n} \min \left(x_{i}, y_{i}\right)$. The $\min$ operator ensures that the lowest score on each axis is considered, what means that cooperative compatibility will increase if and only if the lowest score increases. That happens if and only if respondents have more common expectations from their colleagues during a given cooperative work. Inversely, cooperative compatibility will decrease if and only if the lowest score decreases. That happens if and only if respondents have less common expectations from their colleagues during a given cooperative work. So that the measure performs in accordance with theoretically derived expectations.

2) The measure shows the expected relationships with other measures: There are numerous measures with which cooperative compatibility may be compared in order to study if it shows the expected relationships with other measures: affinity, education level, hierarchical level, etc. Such measures are not only numerous, but also ambiguous. For example it is clear that the more affinity there is, the more will be high cooperative compatibility, and inversely. Nevertheless, no empirical study validating or invalidating that has been found in the scientific literature. We are currently studying the behaviour of cooperative compatibility within industrial fields and particularly regarding to other measures such as notably education level and hierarchical level.

Besides the construct validity of cooperative compatibility, this work is now focusing on ways to understand and to demonstrate how much meaning variance is related to cooperative compatibility. This is a strong postulate of the proposed approach that we are currently testing through industrial fieldworks.

Within organizations, in the context of Computer Supported Cooperative Work in Design, the proposed approach ensures that not only (1) information is shared through information technology, but also (2) meaning variance is predicted through the measurement of cooperative compatibility. Predicting meaning variance allows to share more than just information. We are currently studying through industrial fieldworks how to implement our approach in the context of Computer Supported Cooperative Work in Design. We are notably focusing on the ways to give individuals the means, the time, and the wish to answers forms in order to measure their cooperative compatibilities with the aim of predicting meaning variance.

\section{CONCLUSIONS AND Future Works}

In this paper we presented an approach in order to predict meaning variance between individuals by measuring cooperative compatibility. We began introducing background theories in the area of knowledge management, and particularly on the way different knowledge may be created from the same information. Then we explained and discussed our approach from the interviewing of the respondents to the prediction of meaning variance through the measurement of cooperative compatibility.

A case of cooperative work is given to a sample of respondents. They have to qualify what they expect from their colleagues during the given cooperative work. Their answers are gathered into axes in order to characterize their expectations from their colleagues during the given cooperative work. Then they have to assess themselves on these axes. So that it becomes possible to highlight how much two respondents have common expectations from their colleagues during the given cooperative work. Cooperative compatibility being then higher for respondents with more common expectations.

Relying on knowledge management theories as well as on industrial fieldworks, we argue that the higher cooperative compatibility is, the lower is meaning variance. This is a strong postulate of our work that is discussed in this paper and currently tested within organizations.

Whereas information technology gives individuals the means to share information regardless where they are, cooperative work needs more than just information sharing. Focusing on individuals and on the ways they create knowledge from information leads to understand how much meaning may differ from one person to another. Such understanding allows to imagine how meaning variance may be managed in the future design of Computer Supported Cooperative Work.

\section{ACKNOWLEDGMENT}

The work presented in this paper has been prepared during the $\mathrm{PhD}$ of the author under the direction of Camille RosenthalSabroux and Michel Grundstein. He is grateful to both of them for their support and advice. He would also like to thank the respondents who have accepted to take the time to be interviewed.

\section{REFERENCES}

[1] P-E. Arduin. On the use of cognitive maps to identify meaning variance. Lecture Notes in Business Information Processing, 180:73-80, 2014.

[2] M. Cardona, T. Kretschmer, and T. Strobel. ICT and productivity: conclusions from the empirical literature. Information Economics and Policy, 25(3):109 - 125, 2013.

[3] R.L. Daft and K.E. Weick. Toward a model of organizations as interpretation systems. The Academy of Management Review, 9(2):284$295,1984$. 
[4] J. Greenbaum and M. Kyng. Design at Work: Cooperative Design of Computer Systems. Taylor \& Francis, 1991.

[5] M. Grundstein. New Research on Knowledge Management Models and Methods, chapter Three Postulates That Change Knowledge Management Paradigm. InTech, 2012.

[6] T.K. Haavik. Sensework. Computer Supported Cooperative Work (CSCW), 23(3):269-298, 2014.

[7] B.R. Hornung. Constructing sociology from first order cybernetics: Basic concepts for a sociocybernetic analysis of information society. In Proceedings of the 4th Conference of Sociocybernetics, Corfu, Greece, 2009.

[8] N.A. Jones, H. Ross, T. Lynam, P. Perez, and A. Leitch. Mental models: An interdisciplinary synthesis of theory and methods. Ecology and Society, 16(1), 2011.

[9] B. Jordan. The Design of Computer-Supported Cooperative Work and Groupware Systems, chapter Ethnographic workplace studies and computer supported cooperative work, pages 17-42. North Holland/Elsevier Science, 1996.

[10] A. R. Kearney and S. Kaplan. Toward a methodology for the measurement of the knowledge structures of ordinary people: The conceptual content cognitive map (3CM). Environment and Behavior, 29(5):579617, 1997.

[11] T. Landauer. The Trouble With Computers: Usefulness, Usability, and Productivity. MIT Press, 1995.

[12] Y. Murakami. Hankoten no keizaigaku. Chuo Koron Sha, 1992. (in Japanese).

[13] I. Nonaka and N. Konno. The concept of ba: building a foundation for knowledge creation. California Management Review, 40(3):40-54, 1998.

[14] I. Nonaka and H. Takeuchi. The knowledge-Creating Company. Oxford University Press, 1995.

[15] U. Ozesmi and S. L. Ozesmi. Ecological models based on peoples knowledge: a multi-step fuzzy cognitive mapping approach. Ecological Modelling, 176:43-64, 2004.

[16] M. Polanyi. Personal Knowledge: Towards a Post Critical Philosophy. Routledge, 1958.

[17] M. Polanyi. Sense-giving and sense-reading. Philosophy: Journal of the Royal Institute of Philosophy, 42(162):301-323, 1967.

[18] J.W. Ross, P. Weill, and D. Robertson. Enterprise Architecture As Strategy: Creating a Foundation for Business Execution. Cambridge, Harvard Business School Press, 2006.

[19] K. Schmidt and L. Bannon. Taking CSCW seriously: supporting articulation work. Computer Supported Cooperative Work (CSCW), 1(1):7-40, 1992.

[20] S. Tsuchiya. Improving knowledge creation ability through organizational learning. In ISMICK 1993: Proceedings of the International Symposium on the Management of Industrial and Corporate Knowledge, pages 87-95, 1993.

[21] G. Walsham. Knowledge management: The benefits and limitations of computer systems. European Management Journal, 19(5):599-608, 2001. 